$$
\text { Special Article }
$$

\title{
SCREENING EXTENDED FAMILIES FOR GENETIC HEMOGLOBIN DISORDERS IN PAKISTAN
}

\author{
Suhaib Ahmed, Ph.D., Mohammed Saleem, M.B., B.S., D.C.P., Bernadette Modell, Ph.D., and Mary Petrou, Ph.D.
}

\begin{abstract}
Background We have investigated a strategy for identifying and counseling carriers of recessively inherited disorders in developing countries where consanguineous marriage is common. In such communities, gene variants are trapped within extended families, so that an affected child is a marker of a group at high genetic risk.

Methods Fifteen large Pakistani families, 10 with a history of a hemoglobin disorder and 5 without any such history (controls), were screened for $\beta$-thalassemia and abnormal hemoglobins. All carriers and married couples consisting of two carriers received counseling, and eight families have been followed for two years.

Results In the control families, no carrier was found among 397 members tested. In the 10 families with an index case, 183 of 591 persons tested (31 percent) were carriers; carriers had a 25 percent risk of being in a marriage at risk for producing an affected child, and 17 of 214 married couples (8 percent) consisted of two carriers. No couple at risk was identified among 350 randomly selected pregnant women and their partners. All carriers reported that they have used the information provided in the testing and counseling process: carriers married to carriers with two or more healthy children have avoided further pregnancy, and most such couples with one or no healthy children have used prenatal diagnosis. Seven of eight new marriages and engagements are known not to be at risk.

Conclusions Testing of extended families is a feasible way of deploying DNA-based genetic screening in communities in which consanguineous marriage is common. (N Engl J Med 2002;347:1162-8.)

Copyright $\odot 2002$ Massachusetts Medical Society.
\end{abstract}

A $S$ infant mortality declines, congenital and genetic disorders emerge as important causes of early death and chronic disability, ${ }^{1}$ and developing countries need strategies for integrating genetic approaches into health care. ${ }^{2}$ Pakistan has a population of over 140 million people, 40 percent of whom are younger than 15 years of age; the literacy rate is low, and the average income is $\$ 420$ per year. ${ }^{3}$ The crude birth rate is 29 per 1000 population, and the infant mortality rate is 101 per 1000 live births. The health system is hospital-based, and primary care is practically nonexistent. ${ }^{4}$ As in most of North Africa, the Middle East, and South India, there is a strong cultural preference for consanguineous marriage and an associated relatively high prevalence of recessively inherited disorders. ${ }^{5}$

The hemoglobinopathies are major genetic problems in Pakistan. ${ }^{2}$ About 5 percent of the Pakistani population carries $\beta$-thalassemia, and 0.5 to 1 percent carry hemoglobin $S$ or hemoglobin E. 6,7 Married couples consisting of two carriers have a 25 percent chance that any child they have will be affected. The estimated rate of birth of affected infants is 1.3 per 1000 live births, and about 5250 infants with $\beta$-thalassemia major are born annually. ${ }^{2}$ Although only a minority of these cases are diagnosed, charitable thalassemia centers sustain thousands of affected children with monthly blood transfusions. Such transfusions permit an excellent quality of life during childhood but lead to iron overload and death in adolescence or early adult life. ${ }^{8}$ The average annual cost of iron-chelation therapy with deferoxamine $-\$ 4,400$ per patient, or 10 times the average annual income - is prohibitive. The requirements for treating one annual birth cohort of affected children for one year are 90,000 units of blood plus \$22 million worth of deferoxamine - more than 4 percent of the current health-related expenditures of the government. As treated children began to survive longer, costs might reach 40 percent of current expenditures for health care.

Screening to identify carriers, genetic counseling, and prenatal diagnosis can greatly reduce the rate of birth of affected infants and improve the prognosis of affected patients.9-11 In Pakistan, first-trimester prenatal diagnosis (by chorionic-villus sampling and polymerase chain reaction [PCR]) is not objected to on religious grounds and is acceptable and affordable to

From the Armed Forces Institute of Pathology, Rawalpindi, Pakistan (S.A., M.S.); and the Royal Free and University College Medical School, London (B.M., M.P.). Address reprint requests to Dr. Petrou at the Perinatal Centre, Department of Obstetrics and Gynaecology, Royal Free and University College Medical School, 86-96 Chenies Mews, London WCIE 6HX, United Kingdom, or at m.petrou@ucl.ac.uk.

$1162 \cdot$ N Engl J Med, Vol. 347, No. 15 • October 10, $2002 \cdot$ www.nejm.org 
most families who are at risk. When the fetus is affected, 89 percent of couples choose to terminate the pregnancy. ${ }^{12,13}$ However, the weak health care infrastructure makes it impossible to provide population screening.

In societies in which most couples are unrelated, genes for recessive disorders usually run in families for many generations without manifesting themselves through the birth of an affected child. By contrast, in communities with a cultural preference for consanguineous marriage, as in Pakistan, when a gene for a recessive disorder is present in a kindred, there is likely to be an affected child in at least one branch of the extended family. In turn, the diagnosis of disease in a child serves as a marker of an extended family that is at increased genetic risk. Therefore, in such communities, studies of extended families beginning with the first child with a diagnosis may offer an alternative to population screening for identifying present and future couples at risk for producing affected children. ${ }^{2}$ Our study was designed to test this hypothesis, using hemoglobin disorders as a model.

\section{METHODS}

\section{Study Setting}

We conducted the study at the Armed Forces Institute of Pathology in Rawalpindi (in the northern region of Pakistan), which supports several thalassemia centers that provide care for affected children, testing to identify carriers, counseling, and prenatal diagnosis.

\section{Testing of Extended Families}

Fifteen families of children with a hemoglobin disorder, one family of a carrier of $\beta$-thalassemia, and eight control families with no history of a hemoglobin disorder were offered testing to identify carriers. Criteria for selection were voluntary participation and the availability of many family members. Genetic counseling was conducted according to internationally accepted guidelines. ${ }^{14} \mathrm{~A}$ meeting was arranged with key members of each family (in affected families, usually the parents of the child with the index case) in order to explain the importance of testing to identify other carriers. When family representatives agreed, a three-generation pedigree was drawn up, and arrangements were made for testing family members at their homes. Results were given to the carriers themselves (or to the parents when a carrier was less than 15 years old). The meaning of carrier status, the importance of knowing whether or not one's partner was a carrier, the availability of prenatal diagnosis, and (for those not yet married) the possibility of taking test results into account when planning marriage, were explained orally.

\section{Antenatal Screening}

For comparison with antenatal screening, testing was offered to 350 consecutive women who were attending a local hospital early in their pregnancies. They were informed orally of the relevance of the test and the availability of prenatal diagnosis should they prove to be at risk. When a carrier was identified, her partner was offered immediate testing.

\section{Identification of Carriers}

When the child with the index case had sickle cell anemia, screening to identify carriers was performed by cellulose acetate electrophoresis; red-cell indexes were not measured, because of technical limitations. Screening for thalassemia followed a stepwise approach. First, red-cell indexes (hemoglobin, mean cell volume, and mean cell hemoglobin) were measured with an electronic counter. When there was marked microcytosis (mean cell hemoglobin, $\leqslant 25 \mathrm{pg}$, or mean cell volume, $\leqslant 75 \mathrm{fl}$ ), hemoglobin $\mathrm{A}_{2}$ was measured by cellulose acetate elution ${ }^{15} ; \beta$-thalassemia trait was diagnosed when the percentage of hemoglobin $\mathrm{A}_{2}$ was 3.5 percent or higher. ${ }^{16}$ The specific thalassemia mutations in all affected children and all carriers were identified by PCR with the use of methods that have been described elsewhere. ${ }^{17}$

\section{Follow-up of Families}

The parents of the child with the index case were asked at intervals about engagements, marriages, and births to couples within the family who were at risk of having affected children. It was not possible for investigators to keep track of family members who lived far away, but when affected children were born, they were brought to the center; prenatal diagnosis was performed at the center as well.

\section{RESULTS}

\section{Study Families}

A total of 16 families with an index case of a hemoglobin disorder were approached, and 10 requested testing to identify carriers. The other six families declined for various reasons, including difficulty in getting everyone together, desire to avoid testing because they were apparently healthy, and concern about possible problems in arranging marriages or about the stigma that would be attached to carrier status. Eight control families with no history of a hemoglobin disorder were approached, and five of these families agreed to undergo testing. The other three families declined because of the difficulty of asking people to give blood with no obvious benefit to them.

A typical pedigree of a family with an index case is shown in Figure 1. The 15 study families included a total of 1455 living members (Table 1 ). There were 338 married couples, of which 44 percent were consanguineous (second cousins or closer relatives), 49 percent were from the same biradri (tribe or subdivision of a tribe), and 6 percent were completely unrelated. Although there was considerable interfamily variation in the proportion of marriages that were consanguineous, there was no major difference in the mean proportion between the group of index families and the control group.

The test results are summarized in Table 2. Testing was greatly facilitated when it was supported by an influential family member. It was easiest to undertake testing in rural areas because most people were readily available, whereas in urban areas, men and school-age children were away during the day. Most of those who were not tested live in remote areas; there is no indication that they are at lower risk than the rest of their family.

\section{Index Families}

The index person was an affected child in nine index families and a carrier in one family. The family his- 


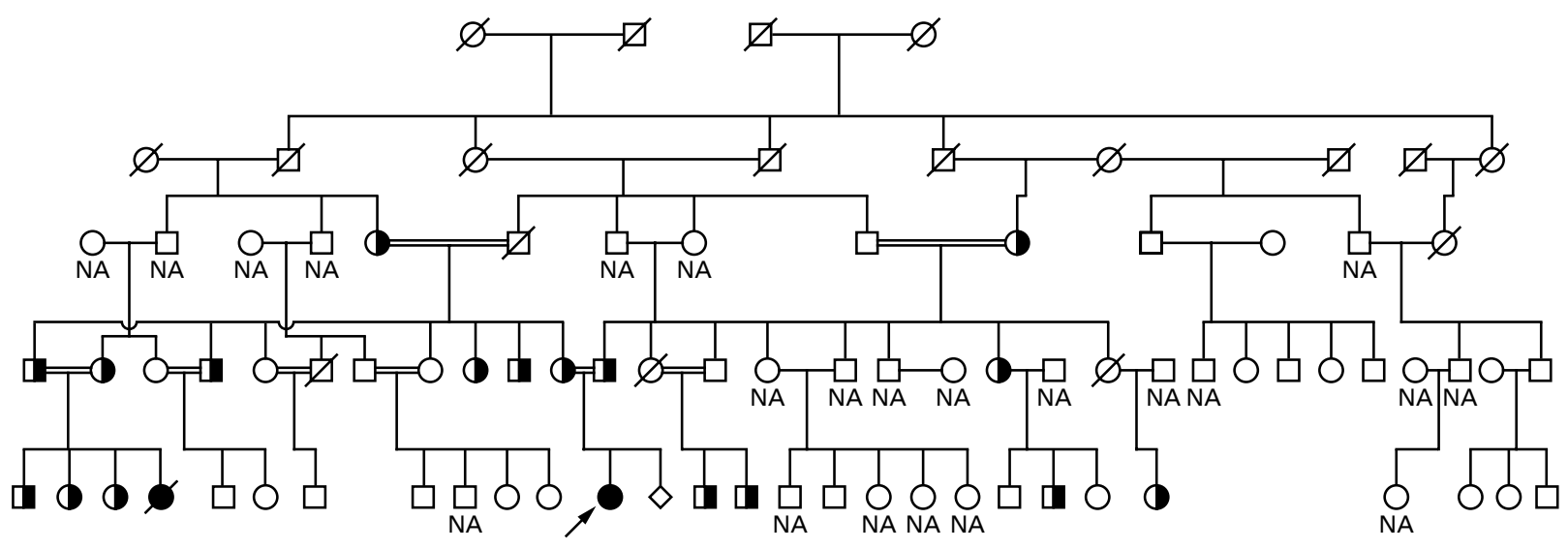

Figure 1. Pedigree and the Results of Testing for $\beta$-Thalassemia in a Typical Index Family.

Circles represent female family members, squares male family members, diamonds children who were born after prenatal diagnosis, half-solid symbols family members who are heterozygous for $\beta$-thalassemia, solid circles female family members with $\beta$-thalassemia major, symbols with a slash family members who are dead, and double lines marriages between first cousins. NA denotes not available for testing. The arrow indicates the index person.

tories revealed that there were another 19 affected children, 6 of whom were alive and 13 of whom had died (Table 2). Of 846 living family members, 591 (70 percent) were tested and 183 ( 31 percent) were found to be carriers. Among the 214 married couples tested, we found 86 carriers, 34 of whom were married to another carrier. Nine of the 17 couples who were at risk were the parents of the child with the index case in their family; 6 more couples consisting of two carriers were identified by the family history (they had already had one or more affected children), and 2 such couples were identified by testing. All couples at risk were informed of the availability of prenatal diagnosis. A total of 97 unmarried carriers were identified and informed of their genetic risk and of the availability of prenatal diagnosis, should their chosen partner also be a carrier.

In Family 8, a carrier had been identified incidentally. Our study showed that a $\beta$-thalassemia gene had entered this family three generations previously through a marriage to a completely unrelated person. The gene was present in only one branch of the family, but Figure 2 shows that the members of the youngest generation in this branch have a high chance of entering a marriage that would be at risk for producing affected children. Although six different mutations were found (Table 2), in 9 of the 10 families we studied all the carriers had the same mutation.

\section{Control Families}

Of 609 living members of the control families, 397 ( 65 percent) were tested, but no carrier was identified.

\section{Antenatal Screening}

All 350 pregnant women who were approached agreed to undergo testing, and 17 of them (5 percent) were found to carry $\beta$-thalassemia. All partners of these 17 women were tested, but no couple was identified as at risk.

\section{Use of Information on Risk}

It has been possible to conduct four years of regular follow-up through informal visits in 8 of the 10 index families. To date, there have been seven new marriages and engagements, and family members said that test results were taken into account when they were arranged. Four consanguineous couples were known not to be at risk; in three, one partner was a known carrier and the other a known noncarrier; and in one, the man was a known noncarrier, so the woman was not tested. One consanguineous couple who had not taken part in the study came spontaneously for premarital testing and was found not to be at risk.

Two men who were carriers and were marrying more "distant" women (one marrying a second cousin, and one marrying within the biradri) married women who had not been tested. In one case, three previous engagements had been broken, the marriage was arranged with difficulty, and the family did not wish to disclose the problem. In the other case, two engagements had been broken after the man's carrier status was disclosed; it was not mentioned during the third engagement, and the bride was found not to be a carrier after marriage. There have so far been no reports that a marriage was avoided explicitly because both partners were carriers. 
Table 1. Characteristics of the 15 Study Families, Including Origin, Size, and Marriage Patterns.

\begin{tabular}{|c|c|c|c|c|c|c|c|c|c|c|}
\hline \multirow[t]{5}{*}{ FamiLy No. } & \multirow[t]{5}{*}{ Condition in Index CASE } & \multicolumn{6}{|c|}{ Characteristics of Family } & \multicolumn{3}{|c|}{ Characteristics of Couples } \\
\hline & & & & & & & & & NO. (\%) & \\
\hline & & & & & & & & NO. $(\%)$ & FROM & \\
\hline & & AREA OF & BIRADRI & NO. OF & No. & NO. $(\%)$ & TOTAL & CONSAN- & SAME & NO. (\%) \\
\hline & & RESIDENCE & OR TRIBE & MEMBERS & MARRIED & UNMARRIED & NO. & GUINEOUS & BIRADRI & UNRELATED \\
\hline \multicolumn{11}{|l|}{ Index families } \\
\hline 1 & $\beta$-Thalassemia major & Urban & Sheikh & 199 & 104 & $95(48)$ & 52 & $20(38)$ & $30(58)$ & $2(4)$ \\
\hline 2 & $\beta$-Thalassemia major & Urban & Awan & 85 & 42 & $43(51)$ & 21 & $15(71)$ & $4(19)$ & $2(10)$ \\
\hline 3 & $\beta$-Thalassemia major & Rural & Khattak & 55 & 28 & $27(49)$ & 14 & $8(57)$ & $5(36)$ & $1(7)$ \\
\hline 4 & $\beta$-Thalassemia major & Rural & Rajpoot & 48 & 24 & $24(50)$ & 12 & $6(50)$ & $4(33)$ & $2(17)$ \\
\hline 5 & $\beta$-Thalassemia major & Rural & Awan & 69 & 38 & $31(45)$ & 19 & $8(42)$ & $9(47)$ & $2(11)$ \\
\hline 6 & $\beta$-Thalassemia major & Urban & Awan & 60 & 28 & $32(53)$ & 14 & $5(36)$ & $9(64)$ & 0 \\
\hline 7 & $\beta$-Thalassemia major & Rural & Khawaja & 80 & 38 & $42(52)$ & 19 & $14(74)$ & $5(26)$ & 0 \\
\hline 8 & $\beta$-Thalassemia trait & $\begin{array}{c}\text { Rural and } \\
\text { urban }\end{array}$ & Sipra & 98 & 56 & $42(43)$ & 28 & $8(29)$ & $15(54)$ & $5(18)$ \\
\hline 9 & Sickle cell anemia & Rural & Bhittani & 79 & 40 & $39(49)$ & 20 & $6(30)$ & $14(70)$ & 0 \\
\hline 10 & Sickle cell anemia & Rural & Bhittani & 73 & 30 & $43(59)$ & 15 & $3(20)$ & $12(80)$ & 0 \\
\hline \multicolumn{11}{|l|}{ Control families } \\
\hline 11 & & Rural & Khattak & 120 & 44 & $76(63)$ & 22 & $13(59)$ & $9(41)$ & 0 \\
\hline 12 & & Rural & Gujar & 72 & 22 & $50(69)$ & 11 & 0 & $11(100)$ & 0 \\
\hline 13 & & Rural & Marwat & 117 & 46 & $71(61)$ & 23 & $6(26)$ & $16(70)$ & $1(4)$ \\
\hline 14 & & Rural & Khattak & 148 & 64 & $84(57)$ & 32 & $19(59)$ & $13(41)$ & 0 \\
\hline 15 & & Rural & Noon & 152 & 72 & $80(53)$ & 36 & $18(50)$ & $14(39)$ & $4(11)$ \\
\hline Total in index families & & & & 846 & 428 & $418(49)$ & 214 & $93(43)$ & $107(50)$ & $14(7)$ \\
\hline Total in control families & & & & 609 & 248 & $361(59)$ & 124 & $56(45)$ & $63(51)$ & $5(4)$ \\
\hline Total in all families & & & & 1455 & 676 & $779(54)$ & 338 & $149(44)$ & $170(50)$ & $19(6)$ \\
\hline
\end{tabular}

In these families to date, no couple at risk with two or more healthy children has undertaken a further pregnancy, and seven prenatal diagnoses have been performed for six couples at risk with no, or only one, healthy child. A couple that was prospectively identified as at risk and that had one unaffected child declined prenatal diagnosis for religious reasons and had an affected child.

\section{DISCUSSION}

We tested the possibility of deploying modern genetic technology appropriately and cost effectively in a developing country. Our hypothesis was that in communities with a cultural preference for consanguineous marriage, gene variants are trapped within extendedfamily groupings. Hence, an affected child is a marker of a group at high genetic risk, and studies of the extended family may identify many carriers and couples at risk before marriage or reproduction. ${ }^{2}$ We tested the hypothesis by offering testing to identify carriers to 16 extended families with a history of a hemoglobin disorder, 8 control families with no such history, and 350 randomly selected pregnant women (for comparison with antenatal screening). About two thirds of the families we approached agreed to undergo testing, and two thirds of their 1455 members were tested.

As would have been expected, 5 percent of the women who were screened early in pregnancy and 31 percent of the members of families with an affected relative were found to be carriers. ${ }^{14,18}$ No carriers were found among 397 members of families with no known affected relative. The results confirm the extremely heterogeneous distribution of gene variants in such populations. ${ }^{19}$

In theory, when the prevalence of carriers is 5 percent in the general population and 31 percent in families with an affected member, a person with an affected relative would have an approximately 1.6 percent chance of entering a marriage at risk for producing affected children ( 31 percent of 5 percent). The index families included 214 couples, 126 of whom were tested. Seventeen couples were found to be at risk - 13 percent of those tested, or at least 8 percent of all couples. Thus, in these families, about 10 percent of couples are probably at risk, and carriers have a 20 to 30 percent chance of entering a marriage at risk for producing affected children.

Of the 17 couples found to be at risk, 11 were closely consanguineous and 6 were related only through the biradri. This finding suggests that variant genes are often trapped not only within extended families, but also in the larger biradri groupings from which many partners are drawn. The proposal that consanguineous marriage should be discouraged in such communities on genetic grounds is ethically unacceptable ${ }^{2}$; it is also unrealistic, because more than 90 percent of marriag- 


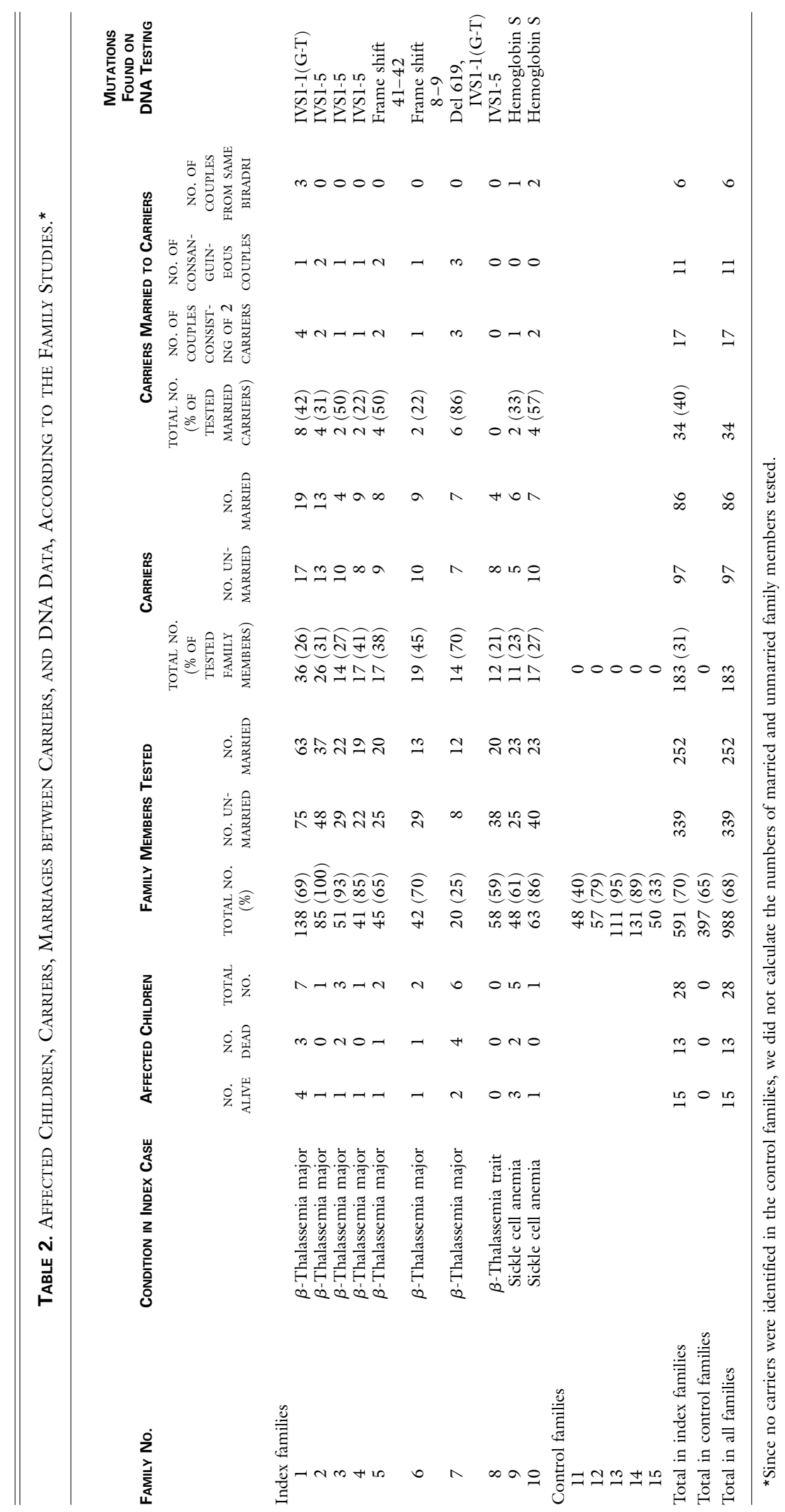

1166 - N Engl J Med, Vol. 347, No. 15 • October 10, $2002 \cdot$ www.nejm.org 


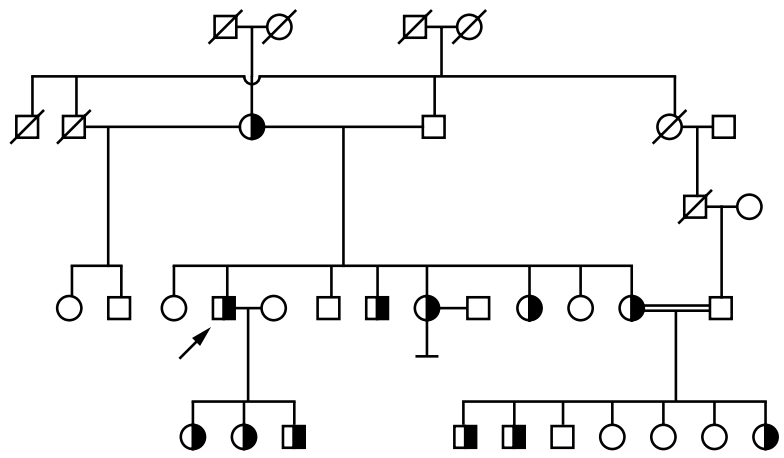

Figure 2. Part of the Pedigree of a Carrier in Family 8 Who Was Incidentally Identified.

The incidentally identified carrier is indicated by an arrow. Circles represent female family members, squares male family members, half-solid symbols family members who are heterozygous for $\beta$-thalassemia, symbols with a slash family members who are dead, and double lines a marriage between first cousins. The $\beta$-thalassemia gene entered the family in the second generation shown, with the female partner in a marriage who was completely unrelated to the male partner. Five of the eight children from this woman's second marriage inherited the gene. So far, two carriers have children, and 5 of 10 possible marriages between first cousins would be at risk of producing an affected child.

es occur within the biradri and logically would have to be discouraged. Such a wholesale attack on social structure has no chance of success. Our study shows that a real option for providing genetic counseling in a way that is compatible with the social mores and kinship structure of the Pakistani population involves accurate testing to identify carriers and the provision of precise information on the presence of risk.

The effectiveness of studies of families is compared with that of population screening in Table 3. Family studies provide a highly effective approach to risk detection in Pakistani society. Population screening is less powerful, but follow-up of carriers can identify increased risk before the birth of any affected child (as it did in the case of Family 8). Therefore, the ideal policy is to provide both family studies and premarital or antenatal screening for the relatives of affected children. This combined approach is a long-term strategy, and its effects are likely to increase with time assuming that ways are found to help families to retain genetic information (which they tend to forget) and to ensure that each new generation is offered testing to identify carriers.

It is worth determining whether persons are at risk only if they wish to know about it and can use the information provided. The main choices open to those who are at risk are avoiding marriage to another carrier or using prenatal diagnosis. Information on carrier
Table 3. Summary of Results of Different Approaches to the Identification of Carriers in Pakistan.

\begin{tabular}{|c|c|c|c|c|c|}
\hline Group & $\begin{array}{l}\text { No. IN } \\
\text { Group }\end{array}$ & $\begin{array}{l}\text { No. } \\
\text { TESted }\end{array}$ & $\begin{array}{l}\text { No. of } \\
\text { CARRIERS }\end{array}$ & $\begin{array}{c}\text { No. of } \\
\text { MARRIED } \\
\text { Couples } \\
\text { CoNTAINING } \\
2 \text { CARRIERS }\end{array}$ & $\begin{array}{c}\text { No. OF } \\
\text { TeStS } \\
\text { PERFORMEd } \\
\text { PER CARRIER } \\
\text { IDENTIFIED }\end{array}$ \\
\hline 10 Index families & 846 & 591 & 183 & 17 & 3.2 \\
\hline 5 Control families & 609 & 397 & 0 & 0 & $>397$ \\
\hline $\begin{array}{l}\text { Randomly selected } \\
\text { pregnant women }\end{array}$ & 350 & 350 & 17 & 0 & 20.6 \\
\hline
\end{tabular}

status has little effect on the choice of partners in Mediterranean countries. ${ }^{10,20}$ This generalization may or may not be applicable in communities in which many marriages are arranged, but there is very little systematic understanding of how such marriages come about - for example, who suggests them, at what age possible partners are identified, and what part is played by the preferences of the young persons themselves. Our observations suggest that close relatives accept marriage with a carrier more easily than unrelated persons do. In the latter situation, it may be particularly difficult for the parents of a woman who is a carrier to ask that a potential partner be tested; most family members said that their preferred solution in such a situation is to postpone testing until after marriage and then to use prenatal diagnosis if required.

As has been reported in Western studies, ${ }^{10,21}$ most couples in our study who were found to be at risk and who had two or more healthy children avoided further pregnancy; many with one healthy child or none requested prenatal diagnosis; and some avoided any intervention in pregnancy for religious reasons. Our observations to date do not permit any firm conclusions other than that many families use information about risk to avoid problems as far as possible.

Our study confirms that in communities in which consanguineous marriage is common, an approach targeting the extended family is useful because it produces a high yield of information on carriers and couples at risk; family members often understand the condition because they have had contact with an affected child; and usually only one gene variant is present in a given family, simplifying and reducing the cost of DNA-based diagnosis. The approach also overcomes problems such as a weak health care infrastructure (because the family study can be undertaken at the center where the index case of the disorder is diagnosed and treated) and a low level of literacy (because information is communicated directly between families with affected children who are attending the center). It is 
also an equitable approach that can be built into services as they are developed and so reach the gradually growing proportion of the population with access to services. In developed countries where labor costs are high, the fact that extended family studies are laborintensive might be a detraction. Since labor costs are proportionate to a country's resources, they are proportionately low in developing countries, where the primary difficulty is the high cost of reagents that must be purchased abroad.

Our study has more than local relevance; the conclusions are applicable for all recessive disorders in populations where consanguineous marriage is common. It is estimated that about 10 percent of congenital and genetic disorders worldwide are associated with customary consanguineous marriage; in most of the Middle East, the proportion is 30 percent, and in Pakistan, it is 40 percent. ${ }^{1,2}$ The growing number of facilities providing DNA-based diagnostic services for hemoglobin disorders provides a basis for far broader clinical molecular-genetics services capable of applying many new techniques for the accurate diagnosis of these disorders. It will take a long time to implement the approach in developing countries; it should be possible to deploy it more rapidly in the sizable communities favoring consanguineous marriage that reside, for example, in the United Kingdom and Scandinavia, ${ }^{22,23}$ where resources for genetic testing are comparatively abundant.

We are indebted to Mir Dar Khan, Farooq Ahmad Khan, Kazim Abbas, Noor Shah Jehan, and Abdul Aziz for technical assistance and help with sample collection.

\section{REFERENCES}

1. Primary health care approaches for the prevention and control of con genital and genetic disorders: report of a WHO meeting, Cairo, Egypt, 6-8 December 1999. Geneva: World Health Organization, 2000. (Document no. WHO/HGN/WG/00.1.

2. Alwan A, Modell B. Community control of genetic and congenital dis- orders. EMRO technical publication series 24. Alexandria, Egypt: WHO Regional Office for the Eastern Mediterranean, 1997.

3. Annual report of health services in Pakistan. Rawalpindi: Ministry of Health, Government of Pakistan, 1997.

4. Burney MI. Health and medical profile of the Muslim world. Islamabad, Pakistan: COMSTECH Secretariat, 1994.

5. Bittles $\mathrm{AH}$. The role and significance of consanguinity as a demographic variable. Pop Dev Rev 1994;20:561-84.

6. Khattak MF, Saleem M. Prevalence of heterozygous $\beta$-thalassaemia in the northern areas of Pakistan. J Pak Med Assoc 1992;42:32-4.

7. Sharma NP, Gupta SC, Atal RR, Melhotra TN, Agarwal AK, Kapoor KK. Abnormal haemoglobins in the Pakistani Armed Forces personnel. Indian J Med Res 1976;64:883-90.

8. Modell $\mathrm{B}$, Berdoukas V. The clinical approach to thalassaemia. London: Grune \& Stratton, 1984.

9. Cao A, Rosatelli MC, Galanello R. Control of beta-thalassaemia by carrier screening, genetic counselling and prenatal diagnosis: the Sardinian experience. Ciba Found Symp 1976;197:137-55.

10. Angastiniotis $M$, Kyriakidou $S$, Hadjiminas $M$. How thalassaemia was controlled in Cyprus. World Health Forum 1986;7:291-7.

11. Loukopoulos D. Current status of thalassaemia and the sickle cell syndromes in Greece. Semin Hematol 1996;33:76-86.

12. Petrou M, Modell B. Prenatal screening for haemoglobin disorders. Prenat Diagn 1995;15:1275-95.

13. Ahmed $S$, Saleem $M$, Sultana $N$, et al. Prenatal diagnosis of $\beta$-thalassaemia in Pakistan: experience in a Muslim country. Prenat Diagn 2000; 20:378-83.

14. Harper PS. Practical genetic counselling. 4th ed. Oxford, England: Butterworth-Heinemann, 1993.

15. The laboratory diagnosis of haemoglobinopathies. Br J Haematol 1998;101:783-92.

16. Steinberg $\mathrm{MH}$, Adams JG III. Haemoglobin $\mathrm{A}_{2}$ : origin, evolution and aftermath. Blood 1991;78:2165-77.

17. Ahmed $S$, Petrou $M$, Saleem M. Molecular genetics of $\beta$-thalassaemia in Pakistan: a basis for prenatal diagnosis. Br J Haematol 1996;94:476-82 18. Mouzouras M, Camba L, Ioannou $P$, Modell $B$, Constantinides $P$,

Gale R. Thalassaemia as a model of recessive genetic disease in the community. Lancet 1980;2:574-8.

19. Rajab A, Patton MA. Analysis of the population structure in Oman. Community Genet 1999;2:23-6.

20. Stamatoyannopoulos G. Problems of screening and counseling in the hemoglobinopathies. In: Motulsky AG, Lenz W, eds. Birth defects. Amsterdam: Excerpta Medica, 1974:268-76.

21. Petrou B, Modell B, Shetty $S$, Khan M, Ward RHT. Long-term effect of prospective detection of high genetic risk on couples' reproductive life: data for thalassaemia. Prenat Diagn 2000;20:469-74.

22. Sickle cell and thalassaemia: achieving health gain: guidance for com missioners and providers. London: Health Education Authority, 1998. 23. Stoltenberg C, Magnus P, Lie RT, Daltveit AK, Irgens LM. Birth defects and parental consanguinity in Norway. Am J Epidemiol 1997;145:439-48.

Copyright (C) 2002 Massachusetts Medical Society. 